\title{
BMJ Global Health Benefiting the NHS through innovation: how to ensure international health partnerships are genuinely reciprocal
}

\author{
Hamdi Issa, ${ }^{1}$ William Townsend, ${ }^{2}$ Matthew Harris (D) ${ }^{1}$
}

\begin{abstract}
To cite: Issa H, Townsend W, Harris M. Benefiting the NHS through innovation: how to ensure international health partnerships are genuinely reciprocal. BMJ Global Health 2021;6:e004936. doi:10.1136/ bmjgh-2021-004936
\end{abstract}

Handling editor Seye Abimbola

Received 4 January 2021 Revised 9 March 2021 Accepted 12 March 2021

Check for updates

(c) Author(s) (or their employer(s)) 2021. Re-use permitted under CC BY-NC. No commercial re-use. See rights and permissions. Published by BMJ.

${ }^{1}$ Department of Primary Care and Public Health, Imperial College London, London, UK

${ }^{2}$ Tropical Health and Education Trust, London, UK

Correspondence to

William Townsend;

william.townsend@thet.org

\section{BACKGROUND}

International health partnerships (IHPs) are institutional arrangements between highincome country (HIC) health institutions and counterparts, usually in low-income and middle-income countries (LMICs), and typically involve secondments or volunteering placements to support clinical delivery, capacity building and health systems strengthening. Increasingly, reciprocity is viewed as key to an effective IHP. ${ }^{1}$ There are few reasons to contest the principle, for example, because it can allow both sides of a partnership to benefit, but it is nonetheless striking how poorly conceptualised it is as a term and practice within IHPs. The report, Global Health Partnerships: the UK contribution to health in developing countries, ${ }^{2}$ placed 'mutual learning' at the core of how institutions should approach IHPs. It propelled the term into global health and IHP domains and, as narratives steer further towards collaboration and mutual benefit, there is a growing imperative to revise partnership models. The appetite for 'collaboration not competition', rooted in principles of 'reciprocity', is taking centre stage. ${ }^{3}$ However, supporting IHPs to bring innovation to the NHS requires clarity on what 'reciprocity', 'mutual learning' and 'mutual benefit' actually mean and how they can be achieved.

In the UK, the Tropical Health and Education Trust (THET) has supported IHPs for the last 30 years and is currently coordinating a flagship IHP programme, UK Partnerships for Health Systems (UKPHS). As THET continues to lead, support and grow its partnership approach, there is need to rethink IHPs to harness the skills, knowledge and technical expertise of LMICs. Investment in IHPs has increased over the last decade and the benefits they bring in terms of technical cooperation for the LMIC are apparent. ${ }^{4}$ The COVID-19 crisis has accelerated the need for
Summary box

To achieve this, partnerships need to transform their approach to knowledge exchanges and coordinating organisations will have to ensure this equilibrium is maintained.

- Genuine reciprocity requires bidirectional learning of technical knowledge (ie, hard skills, innovations, care practices, etc) as well as cultural knowledge (ie knowledge about the country, cultural competency, etc).

- To achieve this, power needs to be acknowledged and accounted for; learning 'about' oneself or the low-income country (LIC) is not a substitute for learning 'from' the LIC, and the propensity for highincome country partners to set the standard for what is 'worthy knowledge' will need continuous and conscious challenge.

- For IHPs to be vehicles for the National Health Service (NHS) to benefit from the innovations of low-income and middle-income countries, technical, as well as cultural, learning is required. Divisions in institutional capacity should not become a barrier to reprocity.

- Reciprocity is poorly conceptualised as a term and practice within international health partnerships (IHPs); however, it is key to an effective IHP and is possible through explicit shared decision-making processes and willingness from both partners to learn technical expertise from each other.

creating genuinely reciprocal partnerships; it has revealed fractures in the UK's public health system and there are clear opportunities to learn from contexts that have responded in a more coordinated and effective manner. However, there is scant evidence of this through IHPs.

Frugal innovations-low-cost and affordable innovations, described as 'means or ends, to do more with less, for the many ${ }^{5}$ have spurred interest in LMICs as sources of innovation. This denotes the emergence of a new frame of mind that perceives LMICs not as passive recipients of expertise but as an equal hotbed for innovations. There are 
multiple opportunities to learn from LMICs ${ }^{6}$ but other than a few notable examples such as oral rehydration sachets, kangaroo care, Ponseti treatment for clubfoot and the GE Mac 400 ECG machine, ${ }^{7}$ there remains a paucity of examples where LMIC innovations have been explicitly adopted into HICs. ${ }^{8}$

In 2019, with funding from Health Education England and the Bill \& Melinda Gates Foundation, THET sought to build the evidence base for such instances through a call for evidence and the funding of Innovation Fellowships. Despite an important example, whereby an NHS surgeon identified an innovation in the use of surgical hernia mesh while volunteering in Tanzania, there were scant examples of where LMIC innovations had been adopted into the NHS, although evidence of innovation within projects was apparent.

The call for reciprocity in partnerships ${ }^{9} 10$ means that IHPs and coordinating organisations need to think and act in ways that foster equilibrium, which is often missing from traditional models of development assistance. Explicit shared decision-making processes and willingness from both partners to learn technical expertise from each other can yield genuine reciprocity. To achieve this, partnerships need to transform their approach to knowledge exchanges and coordinating organisations will have to ensure this equilibrium is maintained. In recognition of this, THET and Imperial College London developed an Innovation Toolkit for IHPs, ${ }^{11}$ seeking to highlight the barriers and biases that exist to learning in LMIC contexts by HICs.

\section{SHIFT IN LANGUAGE DOES NOT MEAN A SHIFT IN PRACTICE}

Although reciprocity suggests bidirectional learning, the 'type' of learning deserves scrutiny. The literature showcases examples of IHPs successfully transferring technical expertise to their LMIC partner; ${ }^{4}$ however, the type of learning for HIC partners tends to be described as personal and individual professional development. ${ }^{12}$ Volunteers learn a lot about themselves and the country they are visiting, but less common is learning from that country, and less common still is bringing those lessons into the UK to change practice. This is the difference between technical (ie, hard skills, innovations, care practices, etc) and cultural knowledge (ie, knowledge about the country, cultural competency, etc). While 'soft' skills remain valuable, it can provide a guise for genuine reciprocity.

It is important to distinguish between these types of learning as it can create a dichotomy between HIC and LMIC knowledge and lead to a return to traditional aid relationships where one partner is left indebted. Reciprocal IHPs are those where the type of learning is the same for both partners. If technical support is being provided, it should be provided in both directions. When one partner is providing a less salient knowledge contribution, then there is a risk of perpetuating 'otherness'. ${ }^{13}$
Recognising this, through the UKPHS, IHPs within their applications for funding are having detailed objectives for both UK and LMIC institutions. A stream of funding will also allow IHPs to apply for support to scale-up an innovation from an LMIC to a UK context.

However, diffusion of innovations from LMICs to HICs is not straightforward. There are practical and regulatory barriers common to the adoption of innovations, which can be further complicated by biases, such as LMICs being viewed as recipients, not providers, of expertise. If IHPs are to be vehicles for the NHS to benefit from the innovations of LMICs, then technical, as well as cultural, learning is required. Fundamental, therefore, is recognising and addressing attitudes that knowledge from HICs is superior and cannot be overlooked, but ideas and innovations from LMICs can. This places knowledge contributed by HICs at the top of the proverbial pyramid; for IHPs to be beneficial to the NHS beyond the individual benefit accrued by volunteers, this needs to change.

To support this, shift in practice THET has worked with the NHS Confederation on briefing NHS managers on how to make use of the aforementioned Innovation Toolkit so that the experiences of NHS staff volunteering overseas and the ingenuity of LMIC partners can be leveraged to harness and scale innovation back into the NHS. $^{14}$

\section{FROM CULTURAL LEARNING TO TECHNICAL KNOWLEDGE EXCHANGES}

When HIC and LMIC partners come together in an IHP, different power positions in that partnership will be assumed. HIC partners that refer to themselves as 'equal' to their LMIC partner or that refer to the partnership as 'reciprocal' without careful attention to how it is reciprocal, risk presuming a lack of differential power. When one partner has more resources, there is a risk of the partnership echoing the path dependencies too familiar in traditional aid relations; appreciating resourcefulness is a good step towards an equitable model. Coordinating organisations and partner countries need to be deliberate in their efforts to ensure divisions in institutional capacity do not become a barrier to reciprocity. This can be achieved in several ways.

First, when a partnership is conceived, power needs to be acknowledged and accounted for. It should not be presumed that the HIC partner will be the coordinating organisation or responsible for administering funding. Partners need to be conscious of each other's expertise and challenges; in the same manner that LMIC needs are identified, the needs of the HIC partner must also be identified. No health system is perfect and there are many fragilities in the UK health system. By allowing both partners to come to the partnership with acknowledgements of their own strengths and weaknesses, the playing field can be levelled and increase the chance of reciprocal technical learning. A solitary focus on the challenges 
or needs of LMIC partners places the HIC partner in a position of power and the LMIC partner in a position of subservience; the likelihood of LMIC innovations being identified, let alone transferred to the UK, remains slim. By acknowledging the challenges in each other's realities, partners can continually learn how to learn together and nurture environments for all partners to contribute their expertise. $^{15}$

Second, while there is inherent value in cultural knowledge, it should be a secondary priority to technical knowledge exchanges. Institutions embarking on a partnership should not satisfice themselves by the prospect that individuals involved will benefit personally. The NHS needs to do more with less, so approaching partnerships with the intention of exchanging learning of similar types (eg, technical for technical knowledge) means that IHPs are more likely to be genuinely reciprocal and of benefit to the NHS.

Third, practical steps towards reciprocal IHPs should involve a conscious and continuous challenge to the tendency for HIC partners setting the standard for what is 'worthy knowledge'. Acknowledging how social and institutional relationships may marginalise or silence certain partners, individuals involved in IHPs should be deliberate in questioning their beliefs and ways of working and in consciously exploring alternatives. This can help ensure that the input and knowledge of all partners is valued. ${ }^{16}$

\section{CONCLUSION}

For IHPs to be effective vehicles for the adoption of innovations from LMICs, they need to be genuinely reciprocal, valuing different knowledge systems and giving space for exchange of technical knowledge. Establishing IHPs as equitable partnerships, addressing power imbalances and acknowledging preconceptions regarding resources and resourcefulness is necessary to move towards more equitable partnerships that provide mutual benefit.

Twitter Matthew Harris @drmattjharris

Contributors Previous work and research of $\mathrm{HI}$ and $\mathrm{MH}$ provided the majority of content for this manuscript. Contributions related to Tropical Health and Education Trust came from WT. All authors contributed in writing the manuscript.

Funding This study was funded by Health Education England.

Competing interests None declared.

Patient consent for publication Not required.
Provenance and peer review Not commissioned; externally peer reviewed.

Data availability statement There are no data in this work.

Open access This is an open access article distributed in accordance with the Creative Commons Attribution Non Commercial (CC BY-NC 4.0) license, which permits others to distribute, remix, adapt, build upon this work non-commercially, and license their derivative works on different terms, provided the original work is properly cited, appropriate credit is given, any changes made indicated, and the use is non-commercial. See: http://creativecommons.org/licenses/by-nc/4.0/.

\section{ORCID iD}

Matthew Harris http://orcid.org/0000-0002-0005-9710

\section{REFERENCES}

1 World Health Organisation. Global catalyst group for institutional health partnerships: position statement, 2014. Available: https:// www.who.int/patientsafety/implementation/apps/global-catalystgroup.pdf?ua=1 [Accessed Sep 2020].

2 Crisp N. Global health partnerships: the UK contribution to health in developing countries. Department of Health, 2007.

3 Chisholm G, Green E, Simms B. In Our Mutual Interest. Tropical Health and Education Trust, 2016. Available: http://www.thet.org/ resource-library/in-our-mutual-interest [Accessed Sep 2020].

4 Kelly E, Doyle V, Weakliam D, et al. A rapid evidence review on the effectiveness of institutional health partnerships. Global Health 2015;11:48.

5 Bhatti Y. Frugal innovation: social entrepreneurs' perceptions of innovation under institutional voids, resource scarcity, and affordability constraints [PhD thesis]. University of Oxford, 2014. Available: https://ora.ox.ac.uk/objects/uuid:17121614-7918-4e56bccc-2806c9ecbfb3 [Accessed Sep 2020].

6 Harris M, Bhatti Y, Buckley J, et al. Fast and frugal innovations in response to the COVID-19 pandemic. Nat Med 2020;26:814-7.

7 Skopec M, Issa H, Harris M. Delivering cost effective healthcare through reverse innovation. BMJ 2019;367:I6205.

8 Bhatti Y, Taylor A, Harris M, et al. Global lessons in Frugal innovation to improve health care delivery in the United States. Health Aff 2017;36:1912-9.

9 Crisp N. Turning the world upside down: the search for global health in the twenty-first century. Boca Raton, FL: CRC Press, 2010.

10 Kulasabanathan $\mathrm{K}$, Issa $\mathrm{H}$, Bhatti $\mathrm{Y}$, et al. Do international health partnerships contribute to reverse innovation? a mixed methods study of THET-supported partnerships in the UK. Global Health 2017;13:25.

11 Issa H, Chisholm G. Innovation toolkit for health partnerships. tropical health and education trust, 2019. Available: https://www. thet.org/resources/innovation-toolkit-for-health-partnerships/ [Accessed Sep 2019].

12 Jones A. Envisioning a global health partnership movement. Global Health 2016;12:1.

13 Said EW. Orientalism. New York: Vintage Books, 1978.

14 NHS Confederation. Leveraging the experiences of NHS staff Volunteering overseas to harness innovation: making use of the THET innovation toolkit. NHS Confederation, 2020. Available: https://www.nhsconfed.org/resources/2020/10/leveraging-overseasexperiences [Accessed Nov 2020].

15 Senge P. The Fifth Discipline: The Art \& Practice of the Learning Organization. Sydney: Random House, 1990.

16 Mignolo W. Local histories / global designs: coloniality, subaltern knowledges, and border thinking. Princeton, NJ: Princeton University Press, 2000. 